\title{
From SARS to Ebola - 10 years of disease prevention and control at ECDC
}

A Ammon (Andrea.Ammon@ecdc.europa.eu) ${ }^{1}$

1. European Centre for Disease Prevention and Control (ECDC), Stockholm, Sweden

A decade ago, the European Centre for Disease Prevention and Control (ECDC) appeared as a new player among international health organisations, with the mandate 'to identify, assess and communicate current and emerging threats to human health from communicable diseases' in the European Union (EU) [1]. As part of the ECDC 10-year anniversary celebrations, Eurosurveillance compiled a print issue with a selection of articles published over this period in the journal. The 10 articles, representing a year each, mark the organisation's evolution and show its leadership and influence in the areas of its mandate.

\section{The first five years}

During 2005 to 2010, the focus was on developing the Centre's core functions. ECDC officially started its operations on 20 May 2005 and in the autumn of that year, wild birds were found positive for influenza $A\left(\mathrm{H}_{5} \mathrm{~N}_{1}\right)$ virus in Croatia, Romania, and Turkey. The then newly established ECDC was asked to answer questions from public health experts and policymakers in EU Member States and the European Commission. Without having the current systems and processes, ECDC experts had to 'build the plane while flying'. An editorial by Nicoll in the first year shows that ECDC was, from the very start, able to strategically shape the activities needed to improve the level of preparedness - for influenza and in general - in Europe [2]. Even retrospectively and in the light of the 2009 influenza pandemic, the answers given to the questions posed in the editorial published in 2005 still hold. Some of the issues raised have been addressed in the meantime by the Commission Decision 1082/2013 [3].

One of ECDC's key tasks is to identify threats from current or emerging infectious diseases. In its second year of operations, ECDC presented a proposal to complement the traditional indicator-based surveillance, using epidemic intelligence as an early detection and warning system [4]. Such epidemic intelligence would take into account changes in the information sector, and pick up relevant information from sources such as traditional and social media and others, and analyse it. The proposed framework became the basis for rapid risk assessments, one of the cornerstones of the
Centre's work today and one of its most appreciated outputs.

Another ECDC core function is capacity building. The European Programme for Intervention Epidemiology Training (EPIET) was transferred to ECDC in 2007 and the article by Varela and Coulombier describes the efforts to define and agree on standards for core competencies required for epidemiologists, which still serve as foundation for this important ongoing task [5]. A short-term vision for surveillance of infectious diseases in the EU was presented in October 2005 to ECDC's governing bodies and in 2008, the single EU surveillance database, The European Surveillance System (TESSy), was successfully established. EU-wide supranational surveillance is at the core of ECDC's mandate and the start of TESSy was accompanied by a long-term strategy with challenging goals, with the aim of adding value, on top of national surveillance systems [6]. Even if not all goals have been achieved today, it is of note that TESSy data are increasingly used, also by non-ECDC scientists as basis for their analyses indicated by the increasing numbers of request to access TESSy data. This demonstrates the added value and that TESSy has become a point of reference for EU data on infectious diseases.

The emergence of a new disease in 2003, severe acute respiratory syndrome (SARS), together with a perceived pandemic threat, sparked the establishment of ECDC. The 2009 influenza pandemic could thus be considered its first 'real' test. In June 2009, early in the pandemic, an article was published with contributions from a large group of collaborators from all EU countries, demonstrating the capability of ECDC to rapidly collate and disseminate information necessary for public health action during a public health event [7]. The article specifically pointed out two important features of the pandemic that were confirmed in several publications thereafter: the relatively mild clinical course and children and adolescents as the main groups affected by and involved in indigenous transmission. 


\section{After the pandemic: $2010-14$}

A new era began in 2010, with a focus on further developing disease-specific functions. Antimicrobial resistance (AMR) is one of the most important infectious disease threats today and most likely also in the future. It has increasingly become a crucial aspect of ECDC's work. The article by the ECDC Antimicrobial Resistance and Healthcare-Associated Infections Programme (ARHAI) provides an overview of the initiatives that ECDC undertook from an early stage to improve the understanding of the risks associated with AMR and to support the response [8]. It also demonstrates the priority given to raising awareness about the relevant health threats.

Another example of how ECDC fulfils its mandate to strengthen prevention and control of cross-border threats in Europe is the guidance described in an article by Leitmeyer [9]. Since its finalisation, the European risk assessment guidance for infectious diseases transmitted on aircraft (RAGIDA) has become a de facto reference for many public health authorities in Europe.

Aside from AMR, healthcare-associated infections are a health threat posing a major burden on individual patients and health systems alike. Prior to a pilot point prevalence survey (PPS) of healthcare-associated infections and antimicrobial use survey, ECDC and a large group of experts from all EU countries developed a standardised methodology, training materials, a train-the-trainer course for national PPS coordinating staff, free-of-charge hospital software for data collection and a validation methodology. The article by Zarb et al. describes one of the most complex epidemiological activities ECDC has coordinated: the pilot survey included nearly 20,000 patients from 66 hospitals in 23 European countries [10]. National PPS coordinating staff trained an estimated 2,80o healthcare workers from 1,200 hospitals across Europe to implement the standardised PPS methodology. Besides being impressive on a technical level, it also provided the first (relatively) comparable picture of prevalence of a fast-growing public health concern. The initiative is another important marker of ECDC's role in identifying and communicating serious threats to health.

Evidence-based approaches aim at improving the quality of scientific findings as a basis for decision-making. The article selected for 2013 reflects the growing demand for evidence-based methods (EBM) in some of the Centre's core functions, where the currently available tools do not provide good-enough answers. Rapid risk assessments are usually developed under time constraints and yet need to form the basis of public health decisions. ECDC and an interdisciplinary group of experts developed a conceptual framework of how to address the current gaps [11] and support public health experts in the future to produce rapid assessments using the best available evidence, even when the evidence may still be limited.
Launched as an ECDC initiative in 2008, the European Antibiotic Awareness Day, marked on 18 November each year, is another example of ECDC activities in the area of communication. It has grown to become a European-wide coordinated health campaign, joined by many countries beyond the EU. Several public health organisations (in the United States and Canada, and the World Health Organization) have aligned their respective campaigns on the same day [12].

In addition to the disease programmes on influenza and the ARHAI, programmes on other disease groups such as emerging and vector-borne diseases, foodand waterborne diseases, HIV, sexually transmitted infections and viral hepatitis, tuberculosis, vaccinepreventable diseases and the microbiology team were established; some of them took up their work already in the early days of ECDC. A list with scientific peerreviewed publications from 2005 onwards is available on the ECDC website and illustrates the work done by the programmes and ECDC experts and expert groups [13].

\section{The future}

The selected articles show that ECDC tackled from its very first year cross-border health threats in close collaboration with a network of experts across the EU and beyond. The expertise of these networks is one pillar of ECDC as most, if not all, of ECDC's work is based on the collaboration of numerous colleagues in the countries' national public health institutes, research and other institutions. I would like to express, on behalf of ECDC, my sincere gratitude for their dedication and constructive input during all these years, which have contributed to shaping ECDC.

As the emergence of the Middle East respiratory syndrome coronavirus (MERS-CoV) and the Ebola outbreak in West Africa have recently demonstrated, some of the issues described in the articles are still relevant today, others might emerge in the future, indicating both the complexity and dynamics of infectious diseases. ECDC will continue to deliver independent outputs of high scientific quality and will endeavour to further increase their usefulness and value for decision makers. In this and in line with the recently published recommendations from the second external ECDC evaluation, ECDC will work closely with the countries and the European Commission to support them in facing threats to human health from current or emerging infectious diseases.

Conflict of interest

None declared.

Authors' contributions

Andrea Ammon wrote the editorial and approved the final version before publication. 


\section{References}

1. The European Parliament and the Council of the European Union. Regulation (EC) No 851/2004 of the European Parliament and of the Council of 21 April 2004 establishing A European centre for disease prevention and control. Luxembourg: Official Journal of the European Union. $30 \mathrm{Apr}$ 2004. Available from: http://eur-lex.europa.eu/legal-content/ EN/TXT/PDF/?uri=CELEX:32004R0851\&from $=E N$

2. Nicoll A. Avian and pandemic influenza--five questions for 2006. Euro Surveill. 2005;10(12):210-1. Available from: http:// www.eurosurveillance.org/ViewArticle. aspx?Articleld $=583$ PMID:16371697

3. The European Parliament and the Council of the European Union. Decision No 1082/2013/EU of the European Parliament and of the Council of 22 October 2013 on serious cross-border threats to health and repealing Decision No 2119/98/EC. Luxembourg: Official Journal of the European Union. 5 Nov 2013. Available from: http://eur-lex.europa.eu/LexUriServ/ LexUriServ.do?uri=0J:L:2013:293:0001:0015:EN:PDF

4. Paquet C, Coulombier D, Kaiser R, Ciotti M. Epidemic intelligence: a new framework for strengthening disease surveillance in Europe. Euro Surveill. 2006;11(12):212-4. Available from: http://www.eurosurveillance.org/ViewArticle. aspx?Articleld=665 PMID:17370970

5. Varela C, Coulombier D; Preparedness and Response Unit, European Centre for Disease Prevention and Control, Stockholm, Sweden. Defining core competencies for epidemiologists working in communicable disease surveillance and response in the public health administrations of the European Union. Euro Surveill. 2007;12(8):E070802.2. Available from: http://www.eurosurveillance.org/ViewArticle. aspx?Articleld $=3245$ PMID:17880886

6. Amato-Gauci A, Ammon A. The surveillance of communicable diseases in the European Union--a long-term strategy (20082013). Euro Surveill. 2008;13(26):18912. Available from: http:// www.eurosurveillance.org/ViewArticle.aspx?Articleld $=18912$ PMID:18761915

7. $E C D C$ working group on influenza $A\left(\mathrm{H}_{1} \mathrm{~N}_{1}\right)$ v. Preliminary analysis of influenza $A\left(\mathrm{H}_{1} \mathrm{~N}_{1}\right) v$ individual and aggregated case reports from EU and EFTA countries. Euro Surveill. 2009;14(23):19238. Available from: http://www. eurosurveillance.org/ViewArticle. aspx?Articleld $=19238$ PMID:19531343〈jrn〉

8. ECDC Antimicrobial Resistance and Healthcare-Associated Infections Programme. Antimicrobial resistance 2010: global attention on carbapenemase-producing bacteria. Euro Surveill.2010;15(46):19719. Available from: http://www. eurosurveillance.org/ViewArticle.aspx?Articleld=19719 PMID:21144433</jrn>

9. Leitmeyer K. European risk assessment guidance for infectious diseases transmitted on aircraft--the RAGIDA project. Euro Surveill. 2011;16(16):19845. Available from: http://www. eurosurveillance.org/ViewArticle. aspx?Articleld =19845 PMID:21527131

10. Zarb P, Coignard B, Griskeviciene J, Muller A, Vankerckhoven V, Weist K, et al.; National Contact Points for the ECDC pilot point prevalence survey; Hospital Contact Points for the ECDC pilot point prevalence survey. The European Centre for Disease Prevention and Control (ECDC) pilot point prevalence survey of healthcare-associated infections and antimicrobial use. Euro Surveill. 2012;17(46):20316. Available from: http:// www.eurosurveillance.org/ViewArticle.aspx?Articleld=20316 PMID:23171822

11. Palmer S, Jansen A, Leitmeyer K, Murdoch H, Forland F. Evidence-Based Medicine applied to the control of communicable disease incidents when evidence is scarce and the time is limited. Euro Surveill. 2013;18(25):20507. Available from: http://www.eurosurveillance.org/ViewArticle. aspx?Articleld=20507 PMID:23806298

12. Earnshaw S, Mancarella G, Mendez A, Todorova B, Magiorakos AP, Possenti E, et al.; European Antibiotic Awareness Day Technical Advisory Committee; European Antibiotic Awareness Day Collaborative Group. European Antibiotic Awareness Day: a five-year perspective of Europe-wide actions to promote prudent use of antibiotics. Euro Surveill. 2014;19(41):20928. http://dx.doi.org/10.2807/1560-7917.ES2014.19.41.20928. PMID:25345519

13. European Centre for Disease Prevention and Control (ECDC). List of scientific peer-reviewed publications produced by ECDC staff on behalf of the Centre for the period of January 2005-March 2015. Stockholm: ECDC. [Accessed 21 Aug 2015]. Available from: http://ecdc.europa.eu/en/publications/peerreviewed/Pages/index.aspx 